STUDIA PRAWNO-EKONOMICZNE, t. CIV, 2017

PL ISSN 0081-6841; e-ISSN 2450-8179

S. $11-26$

DOI: $10.26485 /$ SPE/2017/104/1

\title{
Tomasz BEKRYCHT*
}

\section{KRYZYS IDEI TRÓJPODZIAŁU WŁADZY. KILKA UWAG NA TLE WSPÓLCZESNEGO SPORU O TRYBUNAL KONSTYTUCYJNY W POLSCE - PERSPEKTYWA FILOZOFICZNOPRAWNA ${ }^{1}$}

\begin{abstract}
(Streszczenie)
Niemal w każdej książce dotyczącej zagadnienia praworządności i demokracji wskazuje się na ideę trójpodziału władzy jako jedną z podstawowych zasad demokratycznego państwa prawnego.

W polskiej kulturze prawnej i politycznej ostatnich kilku miesięcy pojawił się pewien problem, który nazywany jest powszechnie 'sporem o Trybunał Konstytucyjny', czasami 'sporem o demokrację' lub 'kryzysem wokół Trybunału Konstytucyjnego'. W mojej ocenie nie jest to jedynie spór polityczny, jak najczęściej mówi się o nim w mediach, ale jest trudnym do rozwiązania zagadnieniem filozoficznym. Jego wyjaśnienie i potencjalne rozwiązanie musi sięgnąć do podstawowego aparatu pojęciowego filozofii prawa i samych fundamentów myślenia prawniczego i politycznego. W niniejszym artykule stawiam tezę, że spór ten jest immanentnie wpisany w naszą kulturę prawną i wiąże się ze szczególną pozycją prawa pozytywnego w tej kulturze wraz próbą budowy naukowego prawoznawstwa przez pozytywizm prawniczy.
\end{abstract}

Słowa kluczowe: Trybunał Konstytucyjny; pozytywizm prawniczy; idea trójpodziału władzy; filozofia prawa

\section{Wprowadzenie}

W polskiej kulturze prawnej i politycznej ostatnich kilku miesięcy pojawił się pewien problem, którego zrozumienie - w mojej ocenie - musi sięgnąć do arsenału aparatu pojęciowego filozofii prawa i samych fundamentów myślenia

* Dr hab., prof. UŁ, Uniwersytet Łódzki, Wydział Prawa i Administracji, Katedra Teorii i Filozofii Prawa; e-mail: tomaszbekrycht@wpia.uni.lodz.pl

1 Artykuł powstał w ramach realizacji projektu „Demokratyczna legitymizacja wpływu orzeczeń sądowych na system tworzenia prawa”, nr 2015/19/B/HS5/03114, finansowanego ze środków Narodowego Centrum Nauki. 
prawniczego i politycznego. Problem, o którym tu mowa, jest nazywany powszechnie 'sporem o Trybunał Konstytucyjny', czasami 'sporem o demokrację' czy też 'sporem o państwo prawa lub państwo prawne' lub 'kryzysem wokół Trybunału Konstytucyjnego' (w dalszej części artykułu używam skrótu Spór). Mówię tutaj bardziej o „zrozumieniu” problemu, a nie o jego „rozwiązaniu”, gdyż w tej kwestii - z metodologicznego punktu widzenia uzasadnienia poniżej przytaczanych twierdzeń - chciałbym przyjąć raczej postawę filozoficzną (krytyczną w pozytywnym tego słowa rozumieniu), postawę zdecydowanie zdystansowaną politycznie i emocjonalnie, a nie dogmatyczną (systemową). Biorąc pod uwagę tę ostatnią, to można byłoby nawet przyjąć, że taki problem w ogóle nie istnieje. Natomiast z perspektywy filozoficznej i przyjmowanej w niej postawy krytycznej, wiele zagadnień w realnie istniejących relacjach społecznych (prawnych) jawi się jako problemy bardziej dialektyczne niż systemowe, co prowadzić może nawet do stwierdzeń o niemożliwości jednoznacznego rozwiązania danego problemu, gdyż rozwiązania te wymykają się możliwości ostatecznego uzasadnienia. Piszę o tym na wstępie, aby uniknąć nieporozumień, co do przyjętej postawy metodologicznej i uprzedzić potencjalne zarzuty z perspektywy uzasadnień systemowych (założeń wynikających z przyjętych $\mathrm{w}$ danym systemie prawa). W tym miejscu mogą pojawić się jednak wątpliwości metodologiczne reprezentowane przez co najmniej trzy pytania, tj. czego dotyczy Spór (co jest jego przedmiotem), następnie, czy jest to zagadnienie prawne, czy polityczne i po trzecie, czy może być analizowane jako zagadnienie naukowe. O ile na pierwsze dwa pytania jest dość łatwo odpowiedzieć, bo chodzi o jedno z zagadnień legitymizacji prawa - w tym przypadku chodzi o polityczny spór pomiędzy paradygmatami pozytywizmu prawniczego, idei trójpodziału władzy i idei prawa naturalnego powstały w wyniku konfliktu o warunki poprawności wyboru sędziów Trybunału Konstytucyjnego oraz możliwości innego ukształtowania tej instytucji przez działania władzy ustawodawczej, a tym samym jest to zagadnienie i prawne i polityczne - to z kolei odpowiedź na trzecie z tych pytań transponuje nas do trudnej i spornej problematyki filozofii nauki, generując pytanie o prawoznawstwo i jego naukowość. Nie podejmując w tym miejscu tych zagadnień, gdyż argumentacja musiałaby stanowić oddzielny tekst opisujący sporne tematy podnoszone $\mathrm{w}$ filozofii nauki, przyjmuję w poniższej argumentacji postawę filozoficzna, przy założeniu (kontrowersyjnym), że filozofia nie jest nauką (w szczególności nauką z perspektywy metod scjentyzmu), ale taką aktywnością intelektualną, która ma za zadanie naukę uzasadnić, umożliwić 
i rozwijać ${ }^{2}$, a tym samym „[...] istnieje - jak pisze Jan Woleński - jakaś fundamentalna różnica metodologiczna decydująca o epistemologicznej odmienności filozofii i nauki, o tym właśnie, że argumentacje filozoficzne pracują inaczej (częściowo lub całkowicie) od dowodów naukowych. Chodzi więc o różnice głębokie, wykraczające poza kwestie bibliograficzno-katalogowe"'3. Za Friedrichem Waismannem można byłoby tę różnicę scharakteryzować jako różnicę „,...] pomiędzy wyprowadzeniem konkluzji a zobaczeniem jakiegoś nowego aspektu czy też sprawieniem, aby ktoś inny to zobaczy’" ". Postawa filozoficzna byłaby zatem z jednej strony teorią nauki, z drugiej refleksją nad wszelką rzeczywistością, a jednocześnie i samorefleksją. Chodzi mi o przyjęcie pewnej niepozytywistycznej postawy angażującej, gdyż pozytywistyczna (systemowa) - jak ją określił Leszek Kołakowski - „,[p]róbuje narzucić język, który zwalnia od obowiązku głosów w najważniejszych konfliktach życia ludzkiego i tworzy rodzaj pancerza, co uniewrażliwia na owe ineffabilia mundi, na nieopisywalne - bo jakościowe - dane doświadczenia"5.

Przyjmując taką postawę, można powiedzieć, że nasze myślenie o relacjach społecznych w kategoriach normatywnych - m.in. o prawie - jest niewatpliwie ukształtowane poprzez wzajemny wpływ trzech tradycji, które treściowo określiły ogół naszych tworów kulturowych. Są nimi Ateny, Rzym i Jerozolima. Zrozumienie istoty Sporu - trwającego już tak długo i bez nadziei na jego bezkompromisowe i zadowalające rozwiązanie - musi zatem sięgnąć, moim zdaniem, do źródeł tradycji śródziemnomorskiej i judeochrześcijańskiej, czyli filozoficznej tradycji naszej kultury, aby móc go wyjaśnić i potencjalnie rozwiązać.

$\mathrm{Z}$ punktu widzenia analiz normatywnych wymienione tradycje wykształciły trzy antagonistyczne idee, których urzeczywistnienie może prowadzić do sytuacji konfliktów społecznych, choćby takich jak obecnie istniejący Spór. Pierwszą z nich jest idea pozytywizmu prawniczego. Druga to idea trójpodziału władzy $(\text { władz })^{6}$. Trzecia zaś to idea istnienia obiektywnej słuszności stanów rzeczy, czyli

2 H. Arendt, Polityka jako obietnica, tłum. W. Madej, M. Godyń, Prószyński i S-ka, Warszawa b.r.w., s. 66; L. Wittgenstein, Tractatus logico-philosophicus, thum. B. Wolniewicz, PWN, Warszawa 1970, tezy 4.111 oraz 6.54 .

J. Woleński, Argumenty filozoficzne, w: idem, W stronę logiki, Aureus, Kraków 1996, s. 17.

Cyt. za: J. Woleński, op. cit., s. 15.

L. Kołakowski, Pozytywizm, PWN, Warszawa 1966, s. 227.

6 W zależności od tego, czy ujmujemy zagadnienie legitymizacji prawa na poziomie najwyższej abstrakcji, czy też mamy na myśli poszczególne składniki instytucjonalne idei trójpodziału, możemy mówić albo o ,idei trójpodziału władzy”, albo o ,idei trójpodziału władz”. Jest to zgodne $\mathrm{z}$ argumentacją Carla Schimtta, który rozróżniając te dwa poziomy, pisze, że „[w]ładza ustrojodawcza jest jednolita i niepodzielna. Nie jest ona obok innych «władz» (takich jak władza usta- 
istnienia niezbywalnych, nienaruszalnych uniwersalnych praw, które miałyby przysługiwać każdej jednostce, a które obecnie występują pod szyldem idei praw człowieka. Moim zdaniem, wzajemne przenikanie się tych idei oraz próba ich urzeczywistniania w relacjach społecznych prowadzą czasami do konieczności definiowania na nowo podstaw ustrojowo-politycznych danych społeczności. W niniejszym artykule stawiam tezę, że Spór, o którym mowa powyżej, jest immanentnie wpisany w naszą kulturę prawną i wiąże się ze szczególną pozycją prawa pozytywnego w tej kulturze i próbą budowy naukowego prawoznawstwa przez pozytywizm prawniczy oraz ideą prawa naturalnego. Poniżej krótko omówię każdą z tych idei w ujęciu problemowym, a następnie spróbuję przedstawić te elementy aparatu pojęciowego filozofii prawa, w którym spotykają się one na poziomie fundamentalnym, stanowiącym punkt wyjścia dla legitymizowania prawa i ewentualnie uzasadniania treści jego norm. Rozpocznę od idei pozytywizmu prawniczego, która prowadzi nas do pojęcia autonomii prawa i szczególnej roli prawników w naszej kulturze prawa. Z problematyki, jaka wiąże się z pozytywizmem prawniczym, rodzi się z kolei problematyka idei trójpodziału władzy. Całość - mówiąc metaforycznie - dopina sporne zagadnienie istnienia obiektywnej słuszności stanów rzeczy, często występujące w postaci idei prawa naturalnego. Nie jest moją ambicją analizowanie, syntetyzowanie i konfrontowanie stanowisk prezentowanych w literaturze przedmiotu, co do problematyki Sporu i wspomnianych idei pozytywizmu prawniczego, trójpodziału władzy, prawa naturalnego i opisu różnych poziomów ich wzajemnego przenikania się i licznych sporów stanowisk tych dotyczących, a poniższa charakterystyka problemu stanowi jedynie prezentację własnej refleksji i analizy.

\section{Aporie pozytywizmu prawniczego i idei trójpodziału władzy}

Jednym z elementów, które - z perspektywy filozoficznoprawnej - stanowią istotę Sporu jest konflikt pomiędzy wizją dwóch koncepcji pozytywizmu prawniczego jako modelu epistemologii prawa. Ogólnie można powiedzieć, że idea

wodawcza, wykonawcza i sądownicza) kolejną skoordynowaną z nimi władzą, ale tworzy szeroką podstawę wszystkich innych «władz» i «podziałów władz» (C. Schmitt, Nauka o konstytucji, thum. M. Kurowska, R. Marszałek, Teologia Polityczna, Warszawa 2013, s. 144). Z perspektywy filozoficznej problem ten dotyczy zagadnienia „abstrakcji ideującej”, szeroko omówionej przez Edmunda Husserla (E. Husserl, Badania logiczne, t. II. Badania dotyczace fenomenologii i teorii poznania, cz. I, thum. J. Sidorek, Wydawnictwo Naukowe PWN, Warszawa 2000, s. 131-274), a historycznie znany jest od starożytności - dialog Parmenides Platona (Platon, Parmenides. Teajtet, tłum. W. Witwicki, Wydawnictwo Antyk, Kęty 2002, fragm. 130e-132b). 
ta pojawiła się wraz ze zjawiskiem tzw. 'odczarowania' świata, czyli nadejściem Oświecenia ${ }^{7}$, które po pierwsze - nieco upraszczając - uświadomiło, że monolit aksjologiczny, który przez setki lat utrzymywany był w ramach idei prawa naturalnego (w szczególność w jego wersji teistycznej) jest podważalny, po drugie zaś sprawiło ono, że pojawiła się idea człowieka jako wartości samej w sobie. W konsekwencji spowodowało to pojawienie się potencjalnego i realnego sporu interesów obywatela i elit sprawujących władzę. Człowiek przestał być postrzegany instrumentalnie jako narzędzie realizowania ich interesów, ale jako cel sam w sobie - jako obywatel. Musiała pojawić się zatem jakaś idea organizacyjna, która wprowadziłaby zasady regulujące tę wielce konfliktową relację. Była nią idea prawa pozytywnego, rozumianego jako doskonale działająca forma, która niestety okazała się (zresztą do dnia dzisiejszego) jedynie rozwiązaniem połowicznym zniesienia owego konfliktu interesów, ze względu na konieczność zawarcia w treści norm prawnych konkretnych rozwiązań aksjologicznych, które zgodnie z ideą prawa pozytywnego, muszą wiązać wszystkich jego adresatów. Z kolei pozytywizm prawniczy rozpoczął projekt budowy naukowego prawoznawstwa na wzór scjentystycznej wizji rzeczywistości normatywnej, który to wzór przyjmuje, że podmiot poznania prawa traktuje prawo jako możliwie kompletny przedmiot poznania i że istnieje kompletny algorytm układania stosunków społecznych. Wyrazem takiej tendencji stała się zarówno dogmatyczna wizja nauki prawa oraz statyczno-dynamiczna koncepcja systemu prawa, jak i biurokratyczny system legitymizacji władzy, dla którego prawo jest instrumentem osiagania wyznaczonych normatywnie celów. Zarówno tworzenie, jak i stosowanie prawa poddają się w tym ujęciu czysto logicznym operacjom (metoda formalno-dogmatyczna). Sprzyja to tym samym $z$ jednej strony wyemancypowaniu się prawa pozytywnego - jego autonomii w stosunku do innych tworów kulturowych, z drugiej zaś możliwości traktowania go jako instrumentu zarządzania społeczeństwem. Taka koncepcja prawa występować może w dwóch, wzajemnie konkurencyjnych paradygmatach. W pierwszym z nich prawo jest nakazem 'nieomylnego' ustawodawcy, który ma legitymację większości danego społeczeństwa, rozumianą jako posłuch wobec groźby sankcji. W tym ujęciu prawo daje się bezpośrednio poznać zarówno z perspektywy prawodawcy, jak i adresata prawa, gdyż jest 'gotowym i obiektywnym' przedmiotem aktów poznawczych (pierwotny pozytywizm ${ }^{8}$ ). W XIX-wiecznej

7 M. Horkheimer, T.W. Adorno, Dialektyka oświecenia, thum. M. Łukasiewicz, Wydawnictwo IFiS PAN, Warszawa 1994, s. 19.

8 Terminy ,pierwotny pozytywizm” i ,wyrafinowany pozytywizm” są tu używane czysto technicznie na potrzeby odróżnienia postawy poznawczej i wyrastających z niej dwóch koncepcji 
nauce prawa wpisuje się to m.in. w koncepcję Gesetzesstaat, gdzie porządek prawny jest utożsamiany z porządkiem prawa ustanowionego ${ }^{9}$. Drugi paradygmat uchyla takie proste założenie epistemiczne, dostrzegając problemy epistemologiczne, w szczególności co do koncepcji języka jako medium komunikacyjnego i konieczności zapośredniczenia projektowanej przez ustawodawcę rzeczywistości sferą znaczeń owego medium. W tym ujęciu legitymizacja prawa opiera się na postawie krytyczno-refleksyjnej i uwzględnieniu racji istnienia prawa przez jego adresatów, ale co najistotniejsze - z perspektywy interesującego nas tu zagadnienia Sporu - wzrasta rola prawników (w szczególności władzy sądowniczej) jako swoistych pośredników owych znaczeń. Innymi słowy, w związku z dostrzeżeniem nieredukowalnej roli języka jako nośnika znaczeń normatywnych musi pojawić się medium pomiędzy prawodawcą a adresatami jego norm. Prawnicy (w szczególności sędziowie) stają się zatem książętami $\mathrm{w}$ imperium prawa ${ }^{10}$, gdzie w tzw. trudnych przypadkach (hard cases), w procesie stosowania prawa, decyduja w ramach trzech Hartowskich reguł wtórnych (zmiany, orzekania i uznania) o treści prawa pozytywnego (wyrafinowany pozytywizm) ${ }^{11}$ dla danego rozstrzygnięcia (w szczególności dokonując wykładni operatywnej). „Jeśli za strategię pozytywizmu - pisze Marek Zirk-Sadowski - jako teorii prawa przyjąć wyodrębnienie prawa jako samodzielnego (niezapośredniczonego przez inne dziedziny kultury) aktu poznawczego, to wyrafinowany pozytywizm prawniczy jest jeszcze bardziej pozytywistyczny niż pozytywizm pierwotny. Usunięcie koncepcji suwerena uwolniło bowiem prawo spod zależności epistemicznej od polityki" 12 .

Z kolei w XIX-wiecznej nauce prawa idea ta wpisywała się w koncepcję Richterstaat (szkoła wolnego prawa), którą można scharakteryzować następująco: „Po pierwsze, rozstrzygnięcia prawne nie są nigdy wyłącznie dedukowane $z$ ustawy [...]. Po drugie, ustawa i prawo nie są identyczne. Po trzecie prawo nie jest żadną statystyczną, ustaloną raz na zawsze wielkością, lecz czymś, co bez ingerencji prawodawcy podlega stałym przemianom"'13. Oczywiście koncepcji państwa sędziów nie należy obecnie identyfikować z jakąkolwiek koncepcją

w ramach epistemologii prawa, tak jak jest to przyjęte w: M. Zirk-Sadowski, Prawo a uczestniczenie w kulturze, Wydawnictwo Uniwersytetu Łódzkiego, Łódź 1998.

$9 \quad$ J. Stelmach, Filozoficzne aspekty dyskusji o państwie prawnym, w: G. Skąpska (red.), Prawo w zmieniajacym się społeczeństwie, Wydawnictwo Adam Marszałek, Toruń/Kraków 1992, s. 221.

10 R. Dworkin, Imperium prawa, thum. J. Winczorek, Wolters Kluwer, Warszawa 2006, s. 409.

11 H.L.A. Hart, Pojęcie prawa, thum. J. Woleński, Wydawnictwo Naukowe PWN, Warszawa 1998.

12 M. Zirk-Sadowski, op. cit., s. 30.

13 J. Stelmach, op. cit., s. 223. 
państwa prawnego, a to, czy była nią historycznie, tj. w XIX w. nie poddaję tu weryfikacji, a jedynie - opierając się na treści cytowanego w przypisie artykułu - wykorzystuję w uproszczony sposób dla zilustrowania opisywanej problematyki: „Zaproponowana przez Kantorowicza i Fuchsa koncepcja [Richterstaat] była bezpośrednią reakcją na pozytywizm prawniczy w wersji określanej jako Begriffsjurisprudenz [...] Budowana na gruncie szkoły wolnego prawa socjologia prawa zwraca się przeciwko pozytywistycznemu myśleniu, przeciwko pozytywistycznemu subsumpcyjnemu modelowi stosowania prawa, zasadzie «związanej decyzji sądowej»" 14 .

Tym samym idea trójpodziału władzy nie jest już tylko - jak chciała tego pierwotna, XVIII-wieczna jej idea - kontrolowaniem i potencjalnym powstrzymywaniem autorytarnej władzy ustawodawczej przed naruszaniem kształtującej się idei praw człowieka, ale wynika z istoty prawa pozytywnego, jego immanentnych i niezbywalnych własności, mających swe źródło w specyfice tekstu prawnego jako komunikatu prawodawcy oraz miejsca samego prawa pozytywnego w relacjach społecznych. Idei tej - na co wskazuje powyższa syntetyczna analiza - nie można zatem znieść ani podważać bez popadania w logiczne sprzeczności, chyba że przyjmie się wątpliwe z punktu widzenia obecnej wiedzy epistemologicznej założenie 'pierwotnego' pozytywizmu.

Dodatkowo problem polega tu jeszcze na tym, że idea trójpodziału władzy niesie ze sobą założenie kontynentalnej kultury prawnej o ścisłym rozdzieleniu kompetencji prawodawczych władz z jej silną tezą, że sądy nie mogą tworzyć prawa. W tym znaczeniu władza jest podzielona i niepodzielona: władza ustawodawcza została przy ustawodawcy (i ewentualnie przy władzy wykonawczej ${ }^{15}$ ), a sądownicza nie może tworzyć prawa, ale jedynie je stosować w przypadkach potencjalnych sporów pomiędzy adresatami norm prawnych. Tym samym źródłem prawa nadal pozostaje ustawodawca, a nie prawo samo w sobie, bo ono ma swoje źródło w decyzji ustawodawcy. Innymi słowy, idea trójpodziału władzy z perspektywy założenia ideologicznego, że sądy nie mogą tworzyć prawa skutkuje

14 Ibidem, s. 223.

$15 \mathrm{Na}$ istotną rolę władzy wykonawczej w ,produkcji” i ,reprodukcji” prawa i tym samym fikcję paradygmatu trójpodziału władz zwraca uwagę w swoim studium Jürgen Habermas: „W tej mierze, w jakiej przykładowo wykonywanie programów celowych obarcza administrację, zadaniami organizacyjnymi, które przynajmniej implicite mają charakter dalszego kształtowania prawa i stosowania ustaw, podstawa legitymizacyjna tradycyjnych struktur administracji już nie wystarcza. Logika podziału władz musi być wtedy realizowana w zmienionych strukturach [...]" (J. Habermas, Faktyczność i obowiazywanie. Teoria dyskursu wobec zagadnień prawa i demokratycznego państwa prawnego, tłum. A. Romaniuk, R. Marszałek, Scholar, Warszawa 2005, s. 208 i n.). 
tym, iż powiedzenie, że to, co mówi ustawodawca, nie jest prawem zakrawa na contradicto in adiecto, bo to przecież jego akt woli staje się dopiero kryterium oceny bezprawia. W związku z tym mamy do czynienia z paradoksalną sytuacją. Argumenty epistemologiczne wskazują na konieczność porzucenia tradycyjnego rozumienia idei trójpodziału władzy i odrzucenia 'pasywnej' roli sądów oraz przyjęcia twierdzenia, że jednak mogą one tworzyć prawo. Z drugiej strony mamy tradycję prawa kontynentalnego (z tezą o tym, że sądy jedynie stosują prawa, czyli nie są prawodawca). Sytuację tę można porównać do próby rozwiązania wybranego problemu naukowego w oparciu o jednoczesne stosowanie nieprzystających do siebie teorii, np. mechaniki klasycznej, mechaniki relatywistycznej czy mechaniki kwantowej albo geometrii Euklidesa i geometrii nieeuklidesowych. Tym samym 'żonglownie' między tymi dwoma paradygmatami prowadzi do aporii, co w konsekwencji powoduje niemożliwość rozwiązania Sporu ${ }^{16}$.

Na tę problematykę nakłada się dodatkowo kolejne sporne zagadnienie ontologiczne i epistemologiczne, czyli istnienia i możliwości poznania obiektywnej słuszności stanów rzeczy, wyrażane w historii filozofii prawa ideą prawa naturalnego. Pomijając kwestie kompetencyjne co do władztwa prawodawczego, to $\mathrm{w}$ interesującym nas przypadku kontrowersyjne jest zagadnienie, która ze stron Sporu ma wiedzę o tej ‘jedynej właściwej’, ‘słusznej’ treści normatywnej prawa.

\section{Istota Sporu}

Jeśli teraz spojrzymy na powyższe ustalenia z perspektywy interesującego nas problemu Sporu, to jawi się on jako konflikt pomiędzy zarysowanymi powyżej paradygmatami pozytywizmu prawniczego, idei trójpodziału władzy i idei prawa naturalnego. Wersja 'pierwotna' pozytywizmu przyjmuje, że prawo jest gotowym i skończonym interpretacyjnie przedmiotem danym w decyzji prawodawcy. Wersja 'wyrafinowana' wskazuje wyraźnie, że pomimo to, iż owa dyskrecjonalność potencjalnych decyzji prawników (w szczególności sędziów) jest w pozytywizmie ograniczona koncepcją zamkniętego katalogu źródeł prawa, to nic bardziej mylnego, gdyż granica ta ma jedynie wymiar formalny ze względu na językowe medium komunikatu normatywnego płynącego z tych źródeł - które to źródła (teksty prawa) ze swej istoty nacechowane są wieloznacznością. Stąd przynajmniej w jakiejś części treść prawa pozytywnego jest ustalana w procesie

16 Ciekawe studium wspierające zaznaczoną tu problematykę z perspektywy teorii prawa konstytucyjnego zawiera praca: B. Banaszak, M. Bernaczyk, Aktywizm sędziowski we wspótczesnym państwie demokratycznym, Wydawnictwo Sejmowe, Warszawa 2012. 
stosowania prawa, czyli - ogólnie mówiąc - przez władzę sądowniczą. Stwierdzenie to można uznać jako tezę filozoficzna, gdyż podnosi problemy epistemologiczne, choćby takie jak problematykę aktu poznawczego (znaczenia tekstu prawnego - treści prawa). Nawet jeśli uznamy, że „narzędziem” eliminowania niezbywalnej wieloznaczności treści prawa pozytywnego jest jego wykładnia, to z perspektywy filozoficznej jest to jedna z kulturowych konstrukcji pojęciowych, które mają służyć do analizy i rozwiązywania problemów społecznych. Jest to jedno $\mathrm{z}$ wyjściowych, akceptowanych założeń kulturowych, zdeterminowanych pewną wizją prawa $\mathrm{z}$ jedną z jej koncepcji-idei, tj. ideą trójpodziału władzy. Nie chodzi mi przy tym o stwierdzenie jej błędności czy fałszywości ani o weryfikację czy falsyfikację stwierdzenia o tworzeniu prawa przez sądy, ale o ujawnienie ukrytego w nich (w idei trójpodziału i tworzenia prawa przez sądy) założenia, że w naszej kulturze mamy do czynienia z ich akceptowalnością wspieraną praktyką prawniczą i charakterystycznym dla danej kultury procesem kształcenia prawników, w szczególności zdeterminowaną pozycją tekstu prawnego. „Generalność i abstrakcyjność nazw w nim użytych [tj. w tekście prawnym - T.B.] uniemożliwia jego bezpośrednie zastosowanie do rozstrzygania jednostkowych i konkretnych spraw. Aby mógł spełniać swoją rolę kulturową, musi być poddany opracowaniu w ramach kolejnego dyskursu, zwanego sądowym stosowaniem prawa. W wymiarze politycznym tego zagadnienia stosuje się zasadę trójpodziału władz, zgodnie z którą na podstawie zbioru takich tekstów władza sądownicza samodzielnie i niezawiśle rozstrzyga konflikty między podmiotami poddanymi władzy suwerena. W takim ujęciu prawa bardzo szybko okazało się, że nie jest jasne, czy prawo jako zbiór norm daje się poznać poprzez bezpośrednie rozumienie tekstu prawnego ustanowionego przez legislatywę, czy też otwiera się tutaj pole władzy sądowniczej, która - uzupełniając prawo decyzjami interpretacyjnymi - ostatecznie je kształtuje. Prawo nie jest wówczas tylko wynikiem aktywności legislatywy, ale wspólnym przedsięwzięciem legislatywy, władzy sądowniczej oraz egzekutywy w tym zakresie, w którym interpretuje ona prawo"17. W szczególności dotyczy to takich źródeł, które zawierają charakterystyczne (specyficzne) normy, jak Konstytucja czy akty prawa międzynarodowego publicznego. Niewątpliwie stopień ogólności norm zawartych w tego rodzaju aktach normatywnych siłą rzeczy angażuje konieczność aktywnej roli np. Trybunału Konstytucyjnego w wyznaczaniu treści prawa. W mojej ocenie

17 L. Leszczyński, B. Wojciechowski, M. Zirk-Sadowski, Wykładnia w prawie administracyjnym, w: R. Hauser, Z. Niewiadomski, A. Wróbel, System prawa administracyjnego, t. 4, C.H. Beck, Instytut Nauk Prawnych PAN, Warszawa 2015, s. 149. 
dobrym przykładem szczególnej abstrakcyjności są m.in. tzw. normy programo$w^{18}$, które wyrażają swoiste samozobowiązanie się prawodawcy do realizacji postawionego celu oraz projektują w bardzo ogólny sposób założenia aksjologiczne systemu prawa. Są one swoistego rodzaju abstrakcyjnymi postulatami sformułowanymi na wysokim stopniu ogólności. Pociaga to za sobą wiele problemów interpretacyjnych, np. związanych z określeniem adresatów norm prawnych, którzy mieliby owe postulaty urzeczywistniać. Normy te bowiem tak jak typowe normy prawne nie wyznaczają danego powinnego zachowania się ich adresata celem realizacji określonego przez treść normy celu, ale nakazują jedynie realizację pewnego celu. „Udzielenie odpowiedzi - jak podkreślają T. Gizbert-Studnicki i A. Grabowski - na pytanie, jakiego rodzaju zachowań normy te nakazuja lub zakazuja, wymaga wykonania złożonych operacji argumentacyjnych. Przesłanki takich operacji argumentacyjnych sięgają poza tekst"19. W szczególności chodzi tu o wiedzę empiryczną, czyli wiedzę o relacjach kauzalnych. Biorąc jednak pod uwagę, że normy te dotyczą relacji społecznych, a nie empirycznych, to interpretacja tych norm będzie rodziła permanentne spory, ze względu na nierozstrzygalność związaną z ustaleniem praw przyczynowych rządzących relacjami społecznymi. Oprócz tego normy te - określając swoje cele - odwołują się często do języka ocen, czyli posługują się zwrotami wartościującymi. Z tego względu - jak celnie podsumowują cytowani Autorzy - „,[o]bie wyżej wskazane trudności powodują, że nie sposób bezspornie (i jednoznacznie) ustalić, jakie zachowania są nakazane lub zakazane przez normy programowe. Jeżeli dwaj interpretatorzy akceptują odmienne założenia dotyczące natury rzeczywistości społecznej lub dysponują odmienną wiedzą o rzeczywistości społecznej, to zakres normowania norm programowych mogą określić w odmienny sposób. Z uwagi na nierozstrzygalność wielu sporów dotyczących rzeczywistości społecznej, spory interpretacyjne także stają się nierozstrzygalne" ${ }^{20}$. Wprawdzie TK co do zasady nie orzeka o konstytucyjności aktów, odwołując się do norm programowych, ale tylko co do zasady, gdyż w niektórych przypadkach naruszenie przez ustawodawcę norm programowych mieści się w kognicji Trybunału Konstytucyjnego ${ }^{21}$. Poza tym, jak podkreśla Lech Morawski, „[k]onflikty różnych zasad

\footnotetext{
T. Gizbert-Studnicki, A. Grabowski, Normy programowe w Konstytucji, w: J. Trzciński, Charakter i struktura norm Konstytucji, Wydawnictwo Sejmowe, Warszawa 1997, s. 95-113.

19 Ibidem, s. 99.

20 Ibidem, s. 100.

21 Analiza tej problematyki znajduje się m.in. w: M. Florczak-Wątor, Możliwość kontrolowania przez Trybunat Konstytucyjny swobody ustawodawcy w zakresie realizacji norm programowych, Przegląd Sejmowy 2009/4 (93), s. 111-127.
} 
prawnych, norm programowych, konflikty różnych praw i wolności obywatelskich są codziennością w pracy sędziego konstytucyjnego i nieraz w nieunikniony sposób wikłają go w konieczność dokonywania wyborów, których powinien dokonać prawodawca"22. Do tego biorąc pod uwagę skomplikowaną relację pomiędzy epistemologicznym odróżnieniem kontekstu odkrycia i kontekstu uzasadnienia, to z punktu widzenia pierwszego z kontekstów wydaje się, że sąd konstytucyjny może mieć własną (czasami inną niż ustawodawca) wiedzę empiryczną i własne (inne niż ustawodawcy) założenia aksjologiczne. Jeśli analiza nasza ma pozostać filozoficznoprawną, to nie możemy od kontekstu tego abstrahować. Oczywiście z perspektywy systemu prawa i jego licznych założeń analiza poprawności decyzji stosowania prawa może być jedynie podejmowana z perspektywy kontekstu uzasadnienia, gdzie ,[...] fikcyjny [...] zbiór operacji tam występujących dobrany jest z punktu widzenia uzasadnialności; zastępujemy rzeczywiste myślenie przez takie operacje, które są uzasadnialne, czyli takie, których prawomocność można wykazać”23. Pomija się tu cały zakres związany z podejmowaniem wolicjonalnych decyzji, które jednak - z perspektywy filozoficznoprawnej - są istotnym składnikiem refleksji dotyczącej metody naukowej, a ,[w]ykrycie wszystkich miejsc, w które uwikłane są decyzje, to jedno z najważniejszych zadań epistemologii" ${ }^{24}$. Nie chodzi tu przy tym o analizę realnych procesów psychologicznych i wyjaśnienia genetyczne, ale o zrozumienie perspektywy analiz filozoficznoprawnych, które ujawniają istnienie wielu założeń kulturowo-systemowych o charakterze jak najbardziej transcendentalnym. To, że nie znajdziemy ich w kontekście uzasadnienia jest zrozumiałe właśnie z perspektywy owych założeń, ze względu na realizację przyjętych w tym systemie wartości. Natomiast podejmowana tu analiza filozoficznoprawna nie może ich deprecjonować, gdyż inne są jej zadania. Tu można pokazać, że istnieje warstwa - jak to nazwał Hans Reichenbach - wolicjonalnych rozwidleń, które leżą u podstaw każdej decyzji i które wymykają się racjonalnej rekonstrukcji w oparciu o algorytmy konwencjonalnych struktur danego systemu. I to właśnie z tego punktu widzenia (analizy filozoficznoprawnej) powstaje trudna do rozstrzygnięcia kwestia kompetencji normodawczych w ramach idei trójpodziału władzy. Rola strażnika Konstytucji (negatywnego prawodawcy) przekształca się tym samym w rolę aktywnego kształtowania treści jej norm. Rozbieżność ta ma wpraw-

22 L. Morawski, Zasada trójpodziału władzy. Trybunat konstytucyjny i aktywizm sędziowski, Przegląd Sejmowy 2009/4 (93), s. 67.

23 H. Reichenbach, Trzy zadania epistemologii, thum. W. Sady, Studia Filozoficzne 1989/7-8, s. 207.

${ }^{24}$ Ibidem, s. 208. 
dzie charakter polityczny, ale nie można od niego abstrahować, wziąwszy pod uwagę, że TK jako organ konstytucyjny ma jednak legitymację polityczną, a tym samym i politycznie legitymizowanym jest osoba (osoby) samego interpretatora, co oznacza, że przy konflikcie aksjologicznym nie jest obojętne, kto (personalnie) jest sędzią TK ${ }^{25}$. Nawet jeśli próbuje się wykazać w kontekście uzasadnienia, że istnieje tu możliwość obiektywnego uprawomocnienia założeń empirycznych i aksjologicznych wyrażonych w normach Konstytucji, bo wymaga tego argument z pozycji ustrojowej sędziego, to własności kontekstu odkrycia nie pozostawiaja wattpliwości co do normatywnej roli władzy trybunalskiej i sądowniczej ${ }^{26}$. „Oczywiste jest - jak pisze Sławomira Wronkowska - że ów nieuchronny zakres swobody, który ma sąd konstytucyjny, pozwala mu - w granicach owej swobody - prowadzić określoną politykę, mianowicie wyznaczać stopień, w jakim prawodawca jest obowiązany optymalizować reguły etosu państwa prawa. Zanim jednak gotowi bylibyśmy uznać tę politykę za niebezpieczną, należałoby uświadomić sobie, że jej alternatywą są niekontrolowane działania prawodawcze, skądinąd niedające gwarancji niearbitralności"27. Jeśli przyjmiemy, że istnieją jakieś autonomiczne wartości kultury prawnej, to niezwykle trudno je realizować w paradygmacie pozytywizmu prawniczego ujmowanego z perspektywy epistemologicznej jako gotowy obiekt poznania czy to w wersji 'pierwotnej', czy 'wyrafinowanej' owego pozytywizmu, ze względu na sposób uczestniczenia prawników w tak ujmowanej (pozytywistycznie) kulturze prawnej. Jak pisze M. Zirk-Sadowski: „Instrumentalne uczestniczenie prawnika w kulturze polega na traktowaniu prawa tylko jako środka do osiagnięcia określonego celu i zanegowaniu wzoru ustalania wewnętrznego punktu widzenia na prawo, poprzez udział we względnie

25 Faktyczną ilustrację tej problematyki zawiera opis i komentarz jednego z wyroków TK dokonany przez Jana Woleńskiego, w: idem, Moralność, cena wołowiny i Trybunat, Krytyka Polityczna (art. z dnia 28.01.2015), http://www.krytykapolityczna.pl/artykuly/opinie/20150128/wolenskimoralnosc-cena-wolowiny-i-trybunal-konstytucyjny; stan na 03.06.2016 r. oraz idem, Woleński. Trybunatu Konstytucyjnego klopoty z logika (art. z dnia 26.02.2016), http://m.krytykapolityczna. pl/artykuly/opinie/20150226/wolenski-waga-trybunalu-konstytucyjnego-nie-byla-wytarowana; stan na 03.06.2016 r.

26 O istotnym dla prawoznawstwa, a w szczególności dla filozoficznej analizy dyskursu stosowania prawa, rozróżnieniu kontekstu odkrycia i kontekstu uzasadnienia pisał w wielu swoich pracach Jerzy Wróblewski. Ideę tę wprowadził Hans Reichenbach w pracy Experience and Predication, University of Chicago Press 1938 (§1 Three Tasks of Epistemology - polski przekład Wojciecha Sady: Studia Filozoficzne 1989/7/8).

27 S. Wronkowska, Charakter prawny klauzuli demokratycznego państwa prawnego (art. 2 Konstytucji Rzeczypospolitej Polskiej), w: S. Wronkowska (red.), Zasada demokratycznego państwa prawnego w Konstytucji RP, Wydawnictwo Sejmowe, Warszawa 2006, s. 121. 
autonomicznej grupie zawodowej. Stąd skłonność do poddawania interpretacji znaczeń zawartych w normach prawnych celom politycznym i ekonomicznym. Autonomiczne wartości kultury prawnej przestają bowiem mieć znaczenie poza względnie zintegrowaną wspólnotą zawodową prawników"28.

Tym samym Spór, o którym tu mowa, jest wpisany w pozytywistyczną wizję idei Rechtsstaat - jest jej niezbywalną, immanentną cechą, która - używając tu barwnej metafory - niczym wirus uśpiony w organizmie odżywa, kiedy ten słabnie, targany różnicami aksjologicznymi, co do rozumienia fundamentalnych wartości, leżących u podstaw danej wspólnoty konstytucyjnej. Dlatego - jak trafnie zauważa Adam Sulikowski - ,[j]eśli TK przetrwa burzę, powinien podjąć próbę odzyskania zaufania społecznego, powinien przedstawiać swoje decyzje jako wynik głębokiego namysłu, także w sensie politycznym, jako rezultat nie tylko analizy norm, ale także możliwości politycznej reprezentacji (w sensie materialnym, a nie formalnym) interesów różnych grup społecznych" ${ }^{29}$. Najprostszym remedium na istniejący problem byłaby sytuacja osiagnięcia przez prawodawcę i władzę trybunalską jedności aksjologicznej, która dodatkowo będzie tożsama $\mathrm{z}$ aksjologią adresatów prawa jako podmiotów legitymizujących władzę. Wydaje się jednak, że taki sąd, jako założenie transcendentalne, jest w naszej rzeczywistości społecznej na razie jedynie ideą regulatywną, realizowaną $\mathrm{w}$ postaci założenia $\mathrm{z}$ argumentu ustrojowego. Jednak poziom legitymizacyjny tego argumentu nie jest fundamentalny, gdyż sam uprzednio wymaga uzasadnienia. Istota demokracji polega - jak zauważa Carl Schmitt - na tożsamości prawa i woli jego adresatów, bo wszystkie decyzje mogą dotyczyć tylko tych, którzy je podejmują. „Każda władza niemająca takiego poparcia uchodzi za uzurpację"30. „[S]uwerenność ludu nie ucieleśnia się już-jak zauważa Habermas - w zgromadzeniu obywateli, które można naocznie zidentyfikować. Sprowadza się ona do poniekąd bezpodmiotowych obiegów komunikacyjnych różnych forów i ciał" ${ }^{1}$. I w tym znaczeniu to my sami nadajemy sobie prawa, czyli „podtrzymujemy przy życiu” władzę jako narzędzie realizacji tej idei. Tym samym treść prawa „[...] nie istnieje - jak to określił Habermas - w trans-

\footnotetext{
M. Zirk-Sadowski, op. cit., s. 47.
}

29 A. Sulikowski, Trybunat Konstytucyjny a polityczność. O konsekwencjach upadku pewnego mitu, PiP 2016/4, s. 13-14.

${ }^{30}$ C. Schmitt, op. cit., s. 174.

31 J. Habermas, Faktyczność i obowiazywanie. Teoria dyskursu wobec zagadnień prawa i demokratycznego państwa prawnego, tłum. A. Romaniuk, R. Marszałek, Scholar, Warszawa 2005, s. $150-151$. 
cendentalnej czystości" ${ }^{2}$. Legitymizację współczesnych porządków prawnych widzi tym samym Habermas w idei samookreślenia wspólnoty prawnej, która dokonuje tego porozumieniem w osiągniętym dyskursie. Ową jedność aksjologiczną można byłoby realizować np. w opisywanym i analizowanym już od ponad dwóch dekad przez Habermasa projekcie sfer publicznych ${ }^{33}$. Projekt ten przyjmuje jako swój rdzeń model demokracji deliberatywnej, gdzie opinie obywateli przekształcają się instytucjonalnie w ich wolę, co następnie prowadzi jego twórcę do idei demokracji konstytucyjnej. Nie ma tu gotowych dogmatów, które byłyby nienaruszalne i niepodważalne, lecz permanentny proces wzajemnego uzgadniania indywidualnych i zbiorowych roszczeń wszystkich adresatów prawa i również wzajemnego uczenia się przez te podmioty. Daje to szanse na dyskursywne rozwiązywanie konfliktów, w szczególności poprzez urzeczywistnienie idei wysłuchania publicznego ${ }^{34}$, a także możliwie jak największego udziału adresatów prawa w dyskursie jego stosowania. Dotyczy to całego obszaru norm prawnych, nie wyłączając Konstytucji, która ze względu na swoją szczególną pozycję $w$ hierarchii systemu tym bardziej powinna być dyskutowana, a nie petryfikowana, a w szczególności uzgadniana nie tylko w polskim, ale również-ze względu na wspólną kulturę - w europejskim dyskursie normatywnym. To, czy jest to projekt utopijny, czy realny w swojej realizacji, trudno tu rozstrzygnąć. Nawet jeśli jego realizacja byłaby w większości nierealizowalna, to mogłaby przynajmniej stanowić rodzaj idei regulatywnej.

\section{Bibliografia}

\section{Opracowania}

Arendt Hannah, Polityka jako obietnica, tłum. Wojciech Madej, Mieczysław Godyń, Prószyński i S-ka, Warszawa b.r.w.

Banaszak Bogusław, Bernaczyk Michal, Aktywizm sędziowski we współczesnym państwie demokratycznym, Wydawnictwo Sejmowe, Warszawa 2012.

32 Ibidem, s. 144.

$33 \mathrm{~W}$ rodzimej literaturze przedmiotu zagadnienie to jest szeroko opisywane i analizowane przez Karolinę M. Cern - szczególnie w pracy The Counterfactual Yardstick. Normativity, SelfConstitutionalisation and the Public Sphere, Peter Lang, Frankfurt am Main, Berlin, Bern, Bruxelles, New York, Oxford, Wien 2014.

34 Obszerne studium zagadnienia demokracji deliberatywnej i idei wysłuchania publicznego zawiera praca Piotra W. Juchacza Deliberatywna filozofia publiczna. Analiza instytucji wystuchania publicznego w Sejmie Rzeczypospolitej Polskiej z perspektywy systemowego podejścia do demokracji deliberatywnej, CoOpera Wydawnictwo Instytutu Filozofii UAM, Poznań 2015. 
Cern Karolia M., The Counterfactual Yardstick. Normativity, Self-Constitutionalisation and the Public Sphere, Peter Lang, Frankfurt am Main, Berlin, Bern, Bruxelles, New York, Oxford, Wien 2014.

Dworkin Ronald, Imperium prawa, tłum. Jan Winczorek, Wolters Kluwer, Warszawa 2006.

Florczak-Wątor Monika, Możliwość kontrolowania przez Trybunat Konstytucyjny swobody ustawodawcy w zakresie realizacji norm programowych, Przegląd Sejmowy 2009/4 (93).

Gizbert-Studnicki Tomasz, Grabowski Andrzej, Normy programowe w Konstytucji, w: Janusz Trzciński, Charakter i struktura norm Konstytucji, Wydawnictwo Sejmowe, Warszawa 1997.

Habermas Jürgen, Faktyczność i obowiązywanie. Teoria dyskursu wobec zagadnień prawa i demokratycznego państwa prawnego, tłum. Adam Romaniuk, Robert Marszałek, Scholar, Warszawa 2005.

Hart Herbert L.A., Pojęcie prawa, tłum. Jan Woleński, Wydawnictwo Naukowe PWN, Warszawa 1998.

Horkheimer Max, Adorno Theodor W., Dialektyka oświecenia, thum. Małgorzata Łukasiewicz, Wydawnictwo IFiS PAN, Warszawa 1994.

Husserl Edmund, Badania logiczne, t. II. Badania dotyczace fenomenologii i teorii poznania, cz. I, thum. Janusz Sidorek, Wydawnictwo Naukowe PWN, Warszawa 2000.

Juchacz Piotr W., Deliberatywna filozofia publiczna. Analiza instytucji wystuchania publicznego w Sejmie Rzeczypospolitej Polskiej z perspektywy systemowego podejścia do demokracji deliberatywnej, CoOpera Wydawnictwo Instytutu Filozofii UAM, Poznań 2015.

Kolakowski Leszek, Pozytywizm, PWN, Warszawa 1966.

Kolakowski Leszek, Szukanie barbarzyńcy. Złudzenia uniwersalizmu kulturowego, w: Leszek Kołakowski, Czy diabet może być zbawiony i 27 innych kazań, Znak, Londyn 1984.

Leszczyński Leszek, Wojciechowski Bartosz, Zirk-Sadowski Marek, Wyktadnia w prawie administracyjnym, w: Roman Hauser, Zygmunt Niewiadomski, Andrzej Wróbel, System prawa administracyjnego, t. 4, C.H. Beck, Instytut Nauk Prawnych PAN, Warszawa 2015.

Platon, Parmenides. Teajtet, tłum. Władysław Witwicki, Wydawnictwo Antyk, Kęty 2002.

Reichenbach Hans, Experience and Predication, University of Chicago Press 1938.

Reichenbach Hans, Trzy zadania epistemologii, thum. Wojciech Sady, Studia Filozoficzne 1989/7-8.

Schmitt Carl, Nauka o konstytucji, tłum. Magdalena Kurowska, Robert Marszałek, Teologia Polityczna, Warszawa 2013.

Stelmach Jerzy, Filozoficzne aspekty dyskusji o państwie prawnym, w: Grażyna Skąpska (red.), Prawo $w$ zmieniajacym się społeczeństwie, Wydawnictwo Adam Marszałek, Toruń/Kraków 1992.

Strauss Leo, Prawo naturalne w świetle historii, thum. Tomasz Górski, PAX, Warszawa 1969.

Sulikowski Adam, Trybunat Konstytucyjny a polityczność. O konsekwencjach upadku pewnego mitu, PiP 2016/4.

Wittgenstein Ludwig, Tractatus logico-philosophicus, tłum. Bogusław Wolniewicz, PWN, Warszawa 1970

Woleński Jan, W stronę logiki, Aureus, Kraków 1996.

Woleński Jan, Moralność, cena wołowiny i Trybunat, Krytyka Polityczna (art. z dnia 28.01.2015), http://www.krytykapolityczna.pl/artykuly/opinie/20150128/wolenski-moralnosc-cenawolowiny-i-trybunal-konstytucyjny; stan na 03.06.2016 r. 
Woleński Jan, Trybunału Konstytucyjnego kłopoty z logika (art. z dnia 26.02.2016), http://m. krytykapolityczna.pl/artykuly/opinie/20150226/wolenski-waga-trybunalu-konstytucyjnegonie-byla-wytarowana; stan na 03.06.2016 r.

Wronkowska Sławomira, Charakter prawny klauzuli demokratycznego państwa prawnego (art. 2 Konstytucji Rzeczypospolitej Polskiej), w: Sławomira Wronkowska (red.), Zasada demokratycznego państwa prawnego w Konstytucji RP, Wydawnictwo Sejmowe, Warszawa 2006.

Zirk-Sadowski Marek, Prawo a uczestniczenie w kulturze, Wydawnictwo Uniwersytetu Łódzkiego, Łódź 1998.

Tomasz BEKRYCHT

\title{
A CRISIS OVER THE IDEA OF THE TRIPARTITE SEPARATION OF POWER. SOME REMARKS ON THE GROUNDS OF THE CONTEMPORARY DISPUTE OVER THE CONSTITUTIONAL TRIBUNAL IN POLAND - LEGAL PHILOSOPHY PERSPECTIVE
}

\author{
(Summary)
}

Almost in every book concerning a problem of law and order and democracy the principle of the tripartite separation of power is indicated as one of the basic principles of the democratic state based on the rule of law.

Last months in Poland's legal and political culture a problem appeared which is widely called 'a dispute over the Constitutional Tribunal', 'a dispute over democracy' or 'a crisis regarding the Constitutional Tribunal'. In my opinion, it is not only a political dispute as it is most often presented in the media but it is a philosophical issue difficult to resolve. Its explanation and potential solution must reach basic means of legal philosophy and the grounds of legal and political thinking. In this article I challenge a thesis that the dispute is immanently connected with our legal culture and involves a distinctive position of positive law in that culture with an attempt of creating jurisprudence by legal positivism.

Keywords: the Constitutional Tribunal; legal positivism; the idea of the tripartite separation of powers; legal philosophy 